\title{
UNA APROXIMACIÓN A LA HISTORIA DEL CONVENTO MÍNIMO DE NUESTRA SEÑORA DE LA VICTORIA DE ARAHAL
} (1546-1835)

\author{
POR \\ Jorge Alberto JordÁn FERnÁndeZ \\ Universidad de Sevilla
}

\section{RESUMEN}

El presente artículo tiene como finalidad presentar una síntesis histórica de lo que fue el convento de Nuestra Señora de la Victoria de Arahal, orden de mínimos. Para ello, después de realizar una pequeña contextualización de la orden de los mínimos, pasamos a desarrollar el objeto de nuestro trabajo en tres grandes apartados: la historia, la economía y el patrimonio artístico del convento arahalense a lo largo de sus casi tres siglos de existencia. Unas conclusiones y el repertorio de fuentes y bibliografía cierran el trabajo.

Palabras Clave: Convento, orden de los mínimos, Arahal, historia, economía, arte.

\section{A RAPPROCHEMENT TO THE HISTORY OF THE MINIMAL CONVENT OF NUESTRA SEÑORA DE LA VICTORIA IN ARAHAL (1546-1835)}

\begin{abstract}
Whit this article we're trying to you to present a brief historical introduction about the convent of Nuestra Señora de la Victoria in Arahal, belonging to the order of the minims. To that respect, after a short explanation about this order, we will develop the research in three blocks: history, economy and art treasures of the convent in its nearly three centuries of existence. To finish we include some conclusion, sources and bibliography.
\end{abstract}

KEY WORDS: Convent, order of the minims, Arahal, history, economy, art treasure.

Recibido/Received

Aceptado/Accepted
17-03-2011

30-06-2014 
El presente trabajo tiene como finalidad dar a conocer algunos datos que contribuyan al conocimiento de la historia del convento de Nuestra Señora de la Victoria de la villa de Arahal, que perteneció a la orden de los mínimos. Se enmarca dentro de un proyecto más amplio, objeto de la tesis doctoral en la que actualmente estamos trabajando, que trata de dar a conocer y poner en valor la huella histórica que dejaron los frailes mínimos en el territorio de la actual provincia de Sevilla.

Para ello, comenzamos dando unas breves pinceladas sobre la orden de los mínimos y su presencia en tierras sevillanas, para a continuación entrar en materia con una síntesis histórica sobre el convento de La Victoria de Arahal; unas notas sobre aspectos económicos de dicho convento configuran otro apartado; a la descripción de cómo fueron el edificio conventual y su iglesia se dedica el siguiente apartado; y para finalizar, diremos algunas cosas sobre los frailes, «las piedras vivas», que formaron parte de este convento. Unas breves conclusiones y la reseña acerca de las fuentes y la bibliografía utilizada en la elaboración de esta comunicación ponen fin a la misma.

\section{La orden de los mínimos en la PROvincia de SEVILla}

La orden de los mínimos fue fundada por san Francisco de Paula ${ }^{1}$ en el sur de Italia en 1435, siendo aprobada canónicamente por el Papa Sixto IV el 17 de mayo de 1474; tras las primeras fundaciones en Italia, la orden se fue extendiendo por el resto de Europa. Por lo que se refiere a España, sabemos que el 22 de septiembre de 1492, los Reyes Católicos dieron una real provisión autorizando el establecimiento de los frailes mínimos en sus reinos; en dicha provisión, los monarcas españoles tomaban bajo su especial protección a la nueva orden y permitían a sus vasallos que les «diesen casas, oratorios o limosnas» para poder fundar y mantenerse. ${ }^{2}$ En virtud de dicha real provisión, el año 1493 tuvo lugar la primera fundación de los mínimos en España: el real Convento de Ntra. Sra. de la Victoria de Málaga; inmediatamente después, fundaron en

\footnotetext{
${ }^{1}$ Natural de la villa italiana de Paula, en la región de Calabria, donde nació el 27 de marzo de 1416. A los trece años ingresó en un convento franciscano para vestir el hábito votivo durante un año. Cumplido ese año de promesa, peregrinó junto con sus padres a la ciudad de Asís, y a la vuelta comenzó a hacer vida de ermitaño en las montañas de villa natal; algunos jóvenes, motivados por su ejemplo, le suplicaron que les admitiese por discípulos suyos, a lo que accedió Francisco, permitiendo la construcción de varias celdas en torno a la suya: era el año 1435. En 1483, Francisco, por orden del sumo pontífice, dejó Calabria y se trasladó a Francia, a la corte del rey Luis XI, país en el que permanecería hasta su muerte, acaecida el 2 de abril de 1507. Fue beatificado en 1513 y seis años después canonizado por el papa León X.

${ }^{2}$ Archivo General del Arzobispado de Sevilla (en adelante, AGAS), Gobierno, Órdenes Religiosas Masculinas, legajo 4, expediente 20.
} 
Andújar (1495), Puerto de Santa María (1502) y Écija (1506). Estos cuatro conventos constituyeron la provincia de España tras la celebración del primer capítulo general de la orden a la muerte de su fundador, que tuvo lugar en Roma el año1507. Con el tiempo, las fundaciones fueron aumentando en número, por lo que en el capítulo general de 1535 la provincia de España se dividió en dos, Andalucía y Castilla. En 1602 la provincia de Andalucía volvió a dividirse en otras dos, la de Granada, que quedó finalmente con veinte conventos, y la de Sevilla, con diecisiete. ${ }^{3}$

En el territorio de la actual provincia de Sevilla, la orden de los mínimos contó con diez conventos, de los que siete pertenecieron a la provincia religiosa de Sevilla (Triana, Arahal, Puebla de Cazalla, Aznalcázar, Utrera, Morón de la Frontera y el colegio de Sevilla) y los otros tres a la de Granada (Écija, Osuna y Estepa). De estos diez conventos, todos estaban enclavados en la jurisdicción de la archidiócesis de Sevilla, excepto el de Estepa, que pertenecía a la jurisdicción de la vicaría general de su nombre, un territorio «nullius dioecesis». En la archidiócesis hispalense llegaron a contar con 22 conventos y más de 500 frailes, pero en el s. XIX la orden entró en un período de decadencia y tras el proceso de exclaustración desapareció de nuestro territorio; a finales del s. XIX, con la vuelta de los religiosos a nuestro país, intentaron fundar en Utrera y Granada, fundaciones que no prosperaron, y después en Barcelona, cuyo convento se abrió en 1901. En Sevilla reanudaron su presencia con la apertura de un convento el 15 de noviembre de 1998. Los frailes mínimos, se distinguían por emitir un cuarto voto en su profesión religiosa consistente en vivir una vida de cuaresma perpetua. Englobados en la categoría general de «órdenes mendicantes», se dedicaban al ejercicio de los ministerios sacerdotales y el rezo en comunidad.

Esta orden cuenta también con una rama femenina, de monasterios de clausura, de origen netamente español y cuyo primer cenobio fue el de Andújar (1495), donde un grupo de piadosas jóvenes pidió a Francisco de Paula que les diera a ellas también una regla de vida semejante a la de los frailes; después surgieron otras fundaciones en nuestro país, Francia e Italia. En la archidiócesis de Sevilla llegaron a contar con siete monasterios en los cuales vivían más de 200 monjas. Hoy continúan su presencia entre nosotros en el sevillano barrio de Triana.

Y también con una orden tercera u orden seglar en la que los laicos, de ambos sexos, viven el evangelio según la espiritualidad del santo de Paula, conforme a una regla propia. Su fundación se debe a la insistente petición de personas deseosas de vivir cristianamente comprometidas según su estilo de vida. En esta orden tercera profesaron, entre otros muchos, san Francisco de Sales, san Juan de Dios, san Vicente de Paúl y santa Juana de Valois, reina de Francia.

\footnotetext{
${ }^{3}$ Cfr. Acta capitulorum generalium ordinis minimorum, Roma, 1916, vol. I.
} 
SíNTESIS HISTÓRICA DEL CONVENTO ARAHALENSE

Antes de entrar de lleno en la historia de este convento, queremos realizar una pequeña aproximación al contexto socio-religioso en que se desenvolvió su devenir; según el Catastro de Ensenada (1751), la villa de El Arahal era de señorío, perteneciente a la casa ducal de Osuna. Tenía entonces una población 1.100 vecinos, lo que suponía aproximadamente 4.400 habitantes, repartidos en 750 casas, de las cuales 250 estaban arruinadas. Los pobres de solemnidad eran unos ciento cincuenta. La población religiosa secular se componía de 75 personas, de las cuales 29 eran presbíteros, 4 estaban ordenados «in sacris» y 42 de órdenes menores. La población religiosa regular se distribuía en tres conventos, dos de frailes y uno de monjas; los de frailes eran el de franciscanos reformados o dieguinos, con 24 de comunidad, y el de mínimos, con 18 religiosos; las monjas pertenecían a la orden de Santo Domingo y en su convento vivían unas 30 religiosas.

Entrando ya en materia, comenzamos diciendo que coinciden los dos cronistas mínimos ${ }^{4}$ en señalar que este convento, el duodécimo de los españoles, fue fundado el día de la Ascensión del año 1546, que lo fue entonces el 12 de junio, siendo provincial de Andalucía fray Francisco de Baeza. Lo que ninguno de los dos cronistas dice es que, al parecer, el convento se fundó primero en una ermita dedicada a San Sebastián que existía en la villa, y de la cual hizo donación a los mínimos el conde de Ureña, además de señalar una renta anual de 30.000 maravedís para alimento de sus moradores. ${ }^{5}$

La fundación, como hemos dicho, se debió al conde de Ureña, don Juan Téllez Girón, «último conde, camarero mayor y su mayordomo del emperador Carlos $V »$, y a su mujer, doña María de la Cueva. Fue ésta la primera de las cuatro fundaciones conventuales que los mínimos debieron a la munificencia de estos condes, siendo las otras las de Osuna (1548), Puebla de Cazalla (1555) y Archidona (1556). Tan es así, que el cronista Montoya llegó a escribir: ${ }^{6}$

Tenía ánimo el conde no dejar lugar en su estado donde no sirviese a nuestro padre san Francisco de Paula, con honrar y favorecer a sus hijos, y cumpliera estos deseos si le durara mucho la vida; con su buena muerte cesó esto, y no menos el aumento de los conventos fundados (...).

\footnotetext{
${ }^{4}$ Cfr. Fr. Lucas de Montoya, om, Crónica General de la Orden de los Mínimos de S. Francisco de Paula, Madrid, 1619, libro III, 182; Fr. Juan de MORALES, om, Epítome de la fundación de la provincia de Andalucía de la orden de los Mínimos del glorioso patriarca San Francisco de Paula, Málaga, 1619, 535.

${ }^{5}$ AGAS, Gobierno, Órdenes Religiosas Masculinas, legajo 8, expediente 3.

${ }^{6}$ Fr. Lucas de Montoya, Crónica General..., 73.
} 
El archivo ducal de Osuna conserva varios documentos relativos a esta fundación, de los que hemos tenido noticia gracias a un inventario del mismo procedente del archivo municipal de Osuna. Así, en el legajo $n^{\circ} 3$ de la bolsa $n^{\circ} 4$ había un «traslado dado y signado de Antonio Morales, escribano de Arahal, en 8 de febrero de 1575» de la provisión dada en Osuna el 3 de marzo de 1546 por don Juan Téllez Girón, IV conde de Ureña, mediante la cual «por si y a nombre de la Sra. doña María de la Cueva, su mujer, fundó un convento con la advocación de Ntra. Sra. de la Victoria y san Francisco de Paula, orden de mínimos, en la iglesia y ermita de San Sebastián, que tenían en dicha villa de Arahal», ofreciendo dotar la fundación con 30.000 maravedís de renta anual, «20.000 por el Sr. Conde y 10.000 por la Sra. Condesa», para la manutención de «los trece frailes que había de haber perpetuamente en dicho convento» según lo habían concertado con fray Francisco de Baeza, provincial de dicha orden.

En dicho legajo había también dos traslados «firmados y signados de Juan Solano, escribano de Arahal», de dos escrituras otorgadas ante él en 30 de mayo y 1 de junio de 1549 respectivamente; en la primera de ellas se establecía que la donación de los 30.000 maravedís anuales para dotación del convento por parte de los fundadores se hacía con la condición de que los frailes reservasen la capilla mayor de su iglesia «para que ninguna persona pudiese enterrarse en ella» y prohibiendo a la comunidad que adquiriese propiedades de particulares tanto por compra como por herencia «sino en cuanto fuese necesario para su provisión, y aún en ese caso, arrendándolas y no administrándolas, para que no se defraudasen los diezmos y rentas pertenecientes al estado»; por la segunda de estas escrituras, la comunidad arahalense aceptaba la anterior donación y renunciaba a la promesa que los condes les habían realizado de dar otros 30.000 maravedís y 300 ducados «que asimismo habían ofrecido para edificar cuartos de habitación, respecto a haberlas costeado y estar ya construidas», obligándose dicha comunidad a cumplir «las condiciones de la fundación en toda forma»; estos tres traslados estaban escritos en once hojas de papel común resguardadas con una cubierta de pergamino. ${ }^{7}$

No sabemos si desde la fundación, pero al menos desde los tiempos del cronista Montoya (1619), en el convento arahalense había establecida una cátedra de artes, la cual estuvo funcionando hasta los tiempos de la invasión francesa pues así se desprende de un documento fechado en noviembre de 1810 en el que el vicario de Arahal, don Pedro de Ortiz y Aguado, informa al arzobispado hispalense acerca de unos de los ex religiosos mínimos de Arahal, de quien decía que había sido...

${ }^{7}$ Archivo Municipal de Osuna (en adelante AMO), bolsa no 4, de Morón, Cote y El Arahal, legajo $3, n^{\circ} 2$. 
... lector de filosofía en la cátedra pública que el convento de dicho orden tenía dotada para beneficio de los jóvenes que querían dedicarse a las letras, y habiendo leído tres años continuos filosofía a muchos de los clérigos minoristas y seculares de dicho pueblo con mucho aprovechamiento y según las reglas de política y práctica que se observan en las más cultas universidades y colegios.

El 27 de septiembre de 1621, los frailes de La Victoria «estando juntos y congregados en nuestro capítulo, en las casas del dicho convento», reunidos al son de campana tañida, como tenían por costumbre, entre los que estaban el corrector, fray Luis de Prados, y los frailes Alonso Jiménez, Fernando Balbuena, Francisco Armero, Antonio Meléndez, Luis de Vega, Pedro Zarzosa, Alonso Morales y Francisco Durán, otorgaron un poder ante el escribano de Arahal, Felipe de Mesa, a favor de fray Fernando de Villacreces para que concertara con Andrés de Ocampo, vecino de Sevilla, «o con cualquier otra persona», el precio que se le había de dar «por un retablo que por nuestra orden ha hecho, el cual es grande, para el altar mayor de la iglesia» del mencionado convento, siendo sus dimensiones once varas de alto por ocho de ancho; asimismo, le otorgaban poder para que pudiese cobrar en su nombre de los tesoreros de la Aduana de Sevilla los réditos de un juro que la comunidad había heredado del licenciado Bartolomé Soria Maldonado, «cura que fue de la iglesia mayor de esta villa» de Arahal y por el cual le correspondían cincuenta ducados anuales de réditos. El 1 de octubre, en virtud de dicho poder, fray Fernando de Villacreces otorgaba una escritura ante el escribano de Sevilla Alonso de Escobedo por la que acordaba con Andrés de Ocampo cerrar el precio del retablo en trescientos ducados y valorar las modificaciones realizadas a la traza original en 3.300 reales, a resultas de lo cual se le debían al dicho Ocampo 434 reales, que fray Fernando se comprometía a pagar en cuanto que el retablo estuviese colocado en el altar mayor de la iglesia, a lo que se comprometía Ocampo. ${ }^{8}$

Seguramente la comunidad mínima de La Victoria tuvo algo que ver en la llegada de la congregación de los hermanos obregones, ${ }^{9}$ afiliados a la tercera orden mínima, a Arahal para hacerse cargo del hospital de la Misericordia; este hospital y la capilla anexa al mismo habían estado, desde su fundación en los primeros años del siglo XVI, al cuidado de la cofradía del Santo Cristo de la Misericordia. Por razones que desconocemos, la cofradía cedió la gestión de

\footnotetext{
${ }^{8}$ Cfr. Miguel de Bago y Quintanilla, «Aportaciones documentales (segunda serie)» Documentos para la Historia del Arte en Andalucía, Sevilla, 1928, vol. II, 28-32.

${ }^{9}$ La Mínima Congregación de los Hermanos de los Pobres había sido fundada en Madrid el año de 1567 por Bernardino de Obregón, haciéndose cargo de un hospital adjunto al convento de La Victoria de Madrid; la congregación fue adscrita a la tercera orden de los mínimos. Su fundador falleció el 6 de agosto de 1599, con gran fama de santidad. En 1636 se establecieron en la ciudad de Sevilla, en el hospital del Buen Suceso. Cfr. Ismael Martínez Carretero, El Carmen del Buen Suceso de Sevilla, Sevilla, 2005, 7-12.
} 
hospital y capilla a la congregación de los obregones mediante escritura otorgada ante el escribano de Arahal Marcos de Biedma el año 1664, bajo ciertas condiciones. La cofradía se comprometía a pagar a la congregación anualmente cincuenta ducados a cambio de que la congregación se hiciese cargo de las reparaciones necesarias y de sostener el culto en la ermita, especialmente en Semana Santa y en la pascua del Espíritu Santo. Además, la cofradía debía disponer de la llave del sagrario de la ermita y de unas salas adecuadas en el edificio del hospital para poder guardar sus enseres y archivo y celebrar allí sus cabildos. Estas condiciones se mantuvieron al menos hasta el año 1743 en que cofradía y congregación aceptaron mancomunadamente como patrono de la nueva iglesia que se había de construir al indiano don Juan Leonardo Malo Manrique. ${ }^{10}$

En los inicios de la ocupación francesa de la villa, marzo de 1810, el vicario y los curas de Arahal dirigieron una petición al comisario regio de Sevilla, don Blas de Aranza, ${ }^{11}$ en la que solicitaban les fueran devueltas sus licencias ministeriales a varios ex religiosos mínimos que residían en la villa y les asignaran al servicio de la parroquia «cuya notoria suficiencia, cuyos buenos sentimientos y cuyos caracteres pacíficos los hacen acreedores a la distinción del Rey al amor de este pueblo»; los religiosos mínimos eran los padres Juan Rodríguez, Alonso Ramos y Miguel de Zayas. ${ }^{12}$

En 1813 el administrador de rentas de la Hacienda Nacional de Marchena abrió un expediente «sobre que se le entreguen los documentos y papeles pertenecientes a los extinguidos conventos del Arahal»; de dicho expediente lo único que se conserva es una relación de libros que eran propiedad de los conventos arahalenses, gracias a la cual tenemos una descripción bastante completa del archivo del convento de La Victoria: ${ }^{13}$

- Libros de gastos: hasta trece libros, de los cuales a la mayoría no se les indica fecha, pero algunos sí, y por ellos sabemos que abarcaban los años de $1634-1635,1639,1702,1710-1711,1732,1790$ y $1794-1795$.

- Libros de recibo o ingresos: se conservaban seis libros, de los cuales estaban fechados los de 1614, 1776, 1771-1778, 1777 (de colecturía), 179091 (del ramo de tierras).

${ }^{10}$ Cfr. Paulino Antonio Nieto Jiménez, «Don Juan Leonardo Malo Manrique y el barroco colonial en Arahal» Actas de las IV Jornadas de historia sobre la provincia de Sevilla, Sevilla, 2007, 177-189.

${ }^{11}$ Don Blas de Aranza y Doyle (h. 1744-1813) fue comisario regio de Sevilla entre el 12 febrero y el 23 de noviembre de 1810 «después de que hubiese sido autorizado a abandonar su destino, como era su deseo, por las humillaciones que sufría y los abusos que no podía corregir». Cfr. Alberto GIL NOVALES, Diccionario biográfico de España (1808-1833), Madrid, 2010, t. I, 220-221.

${ }^{12}$ AGAS, Gobierno, Órdenes Religiosas Masculinas, legajo 15, expediente 3.

${ }^{13}$ Manuel Antonio Ramos Suárez, El patrimonio cultural de Marchena y la ocupación napoleónica, Marchena, 1999, 143-144. 
- Libros de cargo y data o de contabilidad: uno de 1767 y otro de 1772-1773.

- Libros de protocolo o de propiedades: uno de 1619 para propiedades, otro del mismo año para censos y tributos a favor del convento.

- Un libro en folio o «prontuario... de misas e ingresos» de los años 1759-1760.

- Dos libros de memorias y obligaciones del convento de 1619 y 1777 y otros dos de lo mismo sin fecha.

- Un «manual de rentas».

- Siete legajos con documentos de propiedades del convento, fundamentalmente escrituras, al parecer dos corrientes (con los números 1 a 50 y otro 51 a 100) y los demás con escrituras antiguas.

- Un legajo con gastos del convento del año 1792.

- Dos «legajitos y libretes callejeros».

- Varias copias de escrituras, recibos y otros documentos sueltos.

- Un inventario de las fincas del Arahal en venta y renta y una relación jurada de los débitos del convento, ambos de 1810.

Es de suponer que toda esta documentación volvió al archivo del convento tras la marcha de los franceses y la reapertura del mismo.

Un nuevo informe del vicario, don Pedro de Ortiz, fechado el 4 de enero de 1821 , con vistas a determinar qué conventos habrían de cerrar sus puertas, dice de éste de Arahal que tenía una comunidad compuesta por siete ordenados «in sacris», que estaba situado en uno de los extremos del pueblo y que contribuía «a la administración del pasto espiritual a los fieles» ayudando a la parroquia «que se halla con pocos sacerdotes, los más de ellos ancianos», por cuya razón era útil que permaneciera abierto «por la extensión de la población, compuesta de más de 2.050 vecinos». Por la misma fecha, otro informe, esta vez del corrector del convento, fray Andrés Tamariz, venía a coincidir con los datos anteriores, añadiendo que «su amplitud o capacidad (sin embargo de las grandes obras que le he hecho) será para doce individuos» y que de los siete religiosos que componían la comunidad, todos ellos querían intentar su secularización, en vista de lo cual, este convento era uno de los firmes candidatos para ser cerrado. ${ }^{14}$ Tras el breve paréntesis del Trienio Liberal, el convento se reabrió, para cerrarse definitivamente en septiembre de 1835, según lo declaraba uno de sus últimos moradores, de quien tratamos más adelante.

${ }^{14}$ AGAS, Gobierno, Órdenes Religiosas Masculinas, legajo 14, expedientes 7-A y 7-B. 
Por lo que respecta a las cofradías vinculadas a este convento, sólo tenemos noticia de que la titulada como del Dulce Nombre de Jesús tenía su sede en la iglesia conventual cuando el 6 de noviembre de 1597 el mayordomo de la misma, Cristóbal García, acordó con el escultor Blas Hernández, vecino de Sevilla, la hechura de una imagen en madera, dorada y policromada, del Niño Jesús «desnudo, en cueros» de una vara de altura, «con su cruz larga en una mano y la otra echando la bendición con su diadema en la cabeza» y también la peana sobre la que iría dicha imagen; el precio se fijó en veinte ducados y la entrega de la imagen para la pascua de Navidad de aquel año. ${ }^{15}$

\section{LA ECONOMÍA CONVENTUAL: PROPIEDADES Y RENTAS}

El fundador y patrono del convento, el conde de Ureña, dotó al convento con 1.800 reales anuales «y no lo pensionó más que en lo usual de la utilidad espiritual del pueblo», según se dice en un documento del año 1775. ${ }^{16}$

Para determinar las propiedades y rentas con que contaba este convento, disponemos de un completo informe, realizado el 17 de mayo de 1764 por fray Juan Antonio Jiménez, secretario de la comunidad; ${ }^{17}$ de acuerdo con los datos contenidos en dicho informe, podemos establecer la siguiente clasificación de bienes y rentas.

\section{Propiedades rústicas.}

La más importante era la llamada hacienda de la Matilla, sita en término de Morón de la Frontera; el origen de esta hacienda fueron «unas casas de campo inferiores con 52 aranzadas de tierra manchón, la mayor parte de viña antigua» que se compraron con el principal de los 30.000 maravedís de renta que el conde de Ureña había consignado para alimento de los religiosos en la fundación del convento. A la fecha del informe, las viñas habían sido arrancadas y sustituidas por olivos de modo que entonces estaba «poblada de 2.032 pies de olivo, que a razón de 40 pies por aranzada, componen 50 aranzadas y tres cuartas», de las cuales 35 y tres cuartas estaban «bajo cerca» y las restantes 15 aranzadas fuera de dicha cerca. Posteriormente, la comunidad compró en el mismo sitio «junto a dicho cercado, que divide el camino de Morón para Marchena» una suerte de

\footnotetext{
${ }^{15}$ Celestino López Martínez, Desde Jerónimo Hernández hasta Martínez Montañés, Sevilla, 1929, 50-51.

${ }^{16}$ AGAS, Gobierno, Órdenes Religiosas Masculinas, legajo 4, expediente 20. Memoria sobre fundaciones, patronatos, observancia de vida cuaresmal, número de religiosos, rentas de todos y cada uno de los conventos de esta provincia de Mínimos de Sevilla. Su autor es el mínimo P. Miguel Cabrera, del colegio san Francisco de Paula de Sevilla.

${ }^{17}$ AGAS, Gobierno, Órdenes Religiosas Masculinas, legajo 8, expediente 3.
} 
50 fanegas de pan sembrar. Toda esta hacienda producía cada año «exclusos los gastos de su cultivo, cogida, etc.» unos 1.200 reales.

Tenía también el convento otra hacienda, llamada de La Banda, término de Arahal, que fue donada a los religiosos en 1708 por su propietario, don Pedro Cazorla Tristán, beneficiado de la parroquia de Santa María Magdalena, y que se componía de «unas casas viejas, bodega y oratorio en que se celebra misa con sus ornamentos de altar (hoy todo decente y renovado) con su lagar, peso, viga y algunos pocos vasos» que, junto a los toneles y tinajas puestos por la comunidad, tenían una capacidad total para almacenar 2.500 arrobas y también una suerte de 14 aranzadas de viña. Toda esta propiedad estaba gravada con tres censos:

- Uno de 160 ducados de principal a favor de una capellanía fundada por Cristóbal de Balbuena.

- Otro de 410 reales y 20 maravedís de principal redimible a favor de una capellanía fundada por Martín Alonso.

- Un tercero de 80 ducados de principal redimible a favor de la colecturía de la parroquia de Santa María Magdalena.

Los réditos anuales que satisfacía el convento por estos tres censos eran 88 reales y 10 maravedís. Además estaba pensionada con «la obligación de mantener misa todos los días de fiesta al año en el oratorio de dicha hacienda en beneficio de los fieles de todo aquel pago» y un curso de filosofía «para los hijos de este pueblo».

Las propiedades del convento en esta hacienda fueron aumentadas por vía de compra, en 37 aranzadas de olivar y 28 aranzadas de viña, que producían anualmente a la comunidad 1.100 reales y «el vino de su consumo».

El mismo don Pedro Cazorla donó también al convento 32 aranzadas de olivar con 1.452 pies en diferentes pagos, que producían anualmente 915 reales, $\mathrm{y}$ un molino de aceite «ya antiguo y viejo» al sitio de El Lobo, en el ruedo de la villa, con «todos sus pertrechos de piedra, viga y vasos» que dejaba una renta anual de 600 reales. La donación de don Pedro incluía dos censos a favor del convento que producían anualmente réditos por valor de 127 reales y 19 maravedís, al tiempo que tenían las siguientes cargas u obligaciones:

- Un censo anual perpetuo de 383 reales sobre el molino, pagadero al marqués de Gandul.

- Tres fiestas solemnes con sermón anuales, a san Nicolás de Bari, san Julián y santo Tomás de Villanueva, por 270 reales.

- Seis misas rezadas el día de los Difuntos, por 24 reales. 
- Seis mantos de anascote «de seis varas y media en su institución» que debían repartirse anualmente a seis mujeres pobres, por 390 reales.

- Una misa cantada anual a la colecturía de la parroquia de Arahal, por 15 reales.

- Para reparos de la hacienda y el molino, 366 reales anuales.

Era propietaria además la comunidad de varias suertes de tierra en el ruedo de Arahal con una superficie total de 18 fanegas y 8 almudes, cuya renta anual se estimaba en 1.336 reales y de varios pedazos de olivares sueltos, con una superficie de 107 aranzadas y cuarta, en los que había 4.480 pies, cuya renta anual se calculaba en 2.714 reales.

Otras hazas de tierra que poseía el convento eran las siguientes:

- Doce fanegas y nueve almudes en el sitio de La Colina, término de Marchena, que rentaban 100 reales anuales.

- Dieciséis fanegas en el sitio de Torrijos, término de Marchena, que rentaban 110 reales anuales.

- Quince fanegas en el camino de Arahal a Paradas, término de Marchena, rentaban 170 reales anuales.

- Doce fanegas y tres almudes en el sitio de La Grana, término de El Arahal, rentaba 144 reales anuales.

Por último, don Pedro Cazorla también donó al convento dos terceras partes de una huerta en el sitio de Molinilla, término de Arahal, con la pensión de dos misas solemnes cantadas cada año a favor del beneficiado de la parroquia de la villa; el convento compró posteriormente la otra tercera parte, con cierta carga a favor de la fábrica parroquial, por lo que poseía la huerta entera, que se componía de fanega y media de riego, fanega y media de arboleda y una fanega de manchón. La renta anual de la huerta eran 800 reales, a los que había que descontar los 30 reales de la misa solemne y los 101 reales y 6 maravedís del censo a favor de la fábrica parroquial.

En resumen, las tierras propiedad del convento consistían en 227 aranzadas de olivar, 42 aranzadas de viña, 124 fanegas y 8 celemines de tierra y una huerta con 4 fanegas; a lo que habría que añadir una bodega y un molino de aceite. Estas propiedades rústicas producían una renta anual de 9.316 reales y 19 maravedís, a la que habría que descontar 1.667 reales y 6 maravedís de las cargas correspondientes a las mismas. Otros beneficios, como el gasto de vino de la comunidad, o cargas, como el mantenimiento de la cátedra de filosofía en el convento o las misas festivas en el oratorio de la hacienda de la Banda, no son valorados económicamente en el mencionado informe. 
Propiedades urbanas.

Tenía el convento otro molino de aceite con todos sus pertrechos «ya antiguo $y$ viejo» dentro de la cerca del convento y cinco casas situadas en diversas calles de la localidad como Membrilla, Asencio Martín, Puerta de Utrera y Portería, todo lo cual le proporcionaba una renta anual de 594 reales.

\section{Rentas y gastos.}

Percibía el convento por réditos de censos y memorias 3.060 reales y 7 maravedís al año. Respecto de las memorias de misas, decía el secretario, que aunque «eran de tabla doscientas sesenta y nueve rezadas y cuarenta y cuatro cantadas», todas las que habían cumplido cincuenta años de su institución o fundación estaban «bajo el tesoro espiritual de la Santa Romana Iglesia, gozando el equivalente fruto que si las aplicásemos, por especial indulto que nos concedió la Santidad de Benedicto XIV $V^{18}$ en su bula Pro Minimis, expedida en 30 de agosto de 1749», por lo que sus obligaciones de misas se habían reducido a ocho cantadas y catorce rezadas.

Las limosnas recibidas de misas, honras, entierros y procesiones se estimaban en unos 2.000 reales anuales.

Por su parte, los gastos anuales del convento ascendían a 4.581 reales y 24 maravedís y se distribuían en las siguientes partidas:

- A la provincia, el prorrateo para «viajes de visitas y capítulos generales» se le pagaban 800 reales.

- Al cabildo municipal de Arahal por «millones, cientos y alcabalas» se le pagaban 154 reales y 29 maravedís.

- Al médico, barbero y cirujano, 400 reales.

- A la botica 100 reales.

- A las lavanderas de la ropa de sacristía y de refectorio, 165 reales.

- Al real subsidio, 245 reales y 32 maravedís.

- Por gastos de sacristía, cera y vestuarios, 2.200 reales.

- De capellanías y hermandades, 365 reales y 31 maravedís.

- Para reparaciones en el convento, 150 reales.

${ }^{18}$ Fue Papa entre 1740 y 1758. 
Todas las anteriores partidas sumaban una renta total de 14.971 reales y 2 maravedís anuales, a la que había que descontar los 6.248 reales y 21 maravedís de gastos y pensiones, por lo que la renta neta anual con que contaba la comunidad para su manutención eran 8.722 reales y 15 maravedís. El informe que citamos al comienzo de este epígrafe, ${ }^{19}$ fechado tan sólo once años después, fijaba para este convento una renta anual total de 25.285 reales, cantidad que creemos nosotros más acorde con la realidad del patrimonio aquí expresado.

\section{Bienes heredables.}

El informe de 1764 también recoge una serie de bienes que bajo la etiqueta de «heredables» suponían una expectativa de aumento del patrimonio conventual, pero que al no estar todavía en la esfera del mismo no eran valorados económicamente; se trataba de tres casas en Arahal, sitas respectivamente en las calles de Serranos, Portería y plaza Corredera, y de una serie de fincas rústicas:

- Del P. Fr. Francisco Brenes heredaría el convento un olivar de 5 aranzadas en el pago de las Jaretas, otro olivar de aranzada y media y 80 estadales en el pago de las Atarazanas, una aranzada de olivar y otra de viña en un pedazo en el pago de la Labrandera y una aranzada de viña en el pago de Arenal Gordo, todo en la villa de Arahal.

- Del P. Fr. Francisco Jiménez Parejo heredaría el convento una aranzada de olivar en el pago del Corchuelo Chico, de Arahal.

- Del P. Fr. Manuel Portillo heredaría una aranzada de olivar y otra de viña en el pago de Barros, también de Arahal.

En total, unas 10 aranzadas de olivar y 3 de viñas que pasarían a formar parte del patrimonio de este convento a la muerte de dichos religiosos.

\section{PATRIMONIO ARTí́sTICO DEL CONVENTO}

Por lo que se refiere al edificio conventual, la única descripción que tenemos es la de la parte del claustro que todavía se conserva en pie: ${ }^{20}$

Adosada al costado de la Epístola de la iglesia, puede estudiarse una nave del claustro bajo, constituida por arcadas de medio punto sobre columnas, que recuerdan las normas estilísticas del siglo XVII.

\footnotetext{
${ }^{19}$ AGAS, Gobierno, Órdenes Religiosas Masculinas, legajo 4, expediente 20.

${ }^{20}$ VV. AA., Catálogo arqueológico y artístico de la provincia de Sevilla, Sevilla, 1939, t. I, 169.
} 
En cuanto a la iglesia, se trataba de un templo de planta rectangular de una sola nave, edificado en el siglo XVII ${ }^{21}$ que fue reconstruido durante el siglo XVIII, añadiéndosele dos naves y también la torre, nos dicen los autores del Catálogo (1939)..$^{22}$ Las cubiertas de la nave central y de la capilla mayor son de artesonado, ambas modernas. En la capilla mayor todavía hoy puede verse un retablo que los mencionados autores datan en el siglo xviII y describían de la siguiente manera:

En su caja principal venérase la imagen Titular, de vestir. En un tabernáculo superior, pequeña imagen de la Inmaculada, del siglo XVIII. También se veneran en el retablo las figuras de san Francisco de Paula y de los arcángeles san Miguel y san Rafael, carentes de interés.

Se completaba la decoración del presbiterio con dos grandes cuadros que representaban el martirio de san Sebastián y la degollación de san Juan Bautista.

Este esquema compositivo del retablo que acabamos de describir, difiere un tanto del que vio Miguel de Bago en 1928, por tanto, antes de la quema que sufrió en julio de 1936, quien era de la opinión de que el retablo mayor tenía que ser el mismo que la comunidad concertó en 1621 con Andrés de Ocampo, y describía así dicho retablo:

En el primer cuerpo se encuentran, en el centro, las esculturas de san Juan Bautista y santa Lucía, y a cada lado un relieve de la vida de san Francisco [de Paula]. En el cuerpo siguiente aparecen san Miguel y san Rafael. La calle central contiene, por último, la Virgen la Victoria, que es la escultura principal del retablo, y que si bien forma parte del primer cuerpo, está algo más elevada que las estatuas del Bautista y de Santa Lucía, y la Purísima, que aún perteneciendo al segundo cuerpo sirve propiamente de remate.

En aquella fecha advertía en dicho retablo «huellas de varias restauraciones», de las cuales la última se realizó en 1927: «Entonces se doró de nuevo todo el retablo y se amplió la hornacina de la Virgen de la Victoria». ${ }^{23}$ Entre la descripción de 1939 y la de 1929 faltan en este retablo las imágenes de san Juan Bautista y santa Lucía y aparece en 1939 la imagen de san Francisco de Paula, que no estaba en 1928. En 1939 tampoco se mencionan los dos relieves con pasajes de la vida del santo de Paula, pero debe tratarse de una omisión, pues todavía hoy pueden verse allí. Al siglo XVIII pertenecen las esculturas de san Miguel, san Rafael, la Inmaculada y san Francisco de Paula. ${ }^{24}$

${ }^{21}$ Un historiador sitúa la fecha de conclusión del templo en 1551, cfr. Antonio Jiménez Pérez, Notas históricas de Arahal, s/1, 1972, 72-73.

${ }^{22}$ VV. AA., Catálogo arqueológico..., 170.

${ }^{23}$ Bago y Quintanilla, Miguel de, Aportaciones documentales..., 28.

${ }^{24}$ VV. AA., Guía artística de Sevilla y su provincia, Sevilla ${ }^{2}$, 2004, t. II, p. 125. 
Siguiendo a los autores del Catálogo, a la cabecera de la nave del evangelio se situaba la capilla sacramental con un retablo neoclásico ${ }^{25}$ presidido por una imagen de vestir de la Virgen del Carmen, imagen que hoy sustituye a la de la Victoria en el altar mayor; en las pechinas que sostienen la cúpula de esta capilla hay pintados al óleo sobre tabla los cuatro evangelistas, obras del siglo XVI. ${ }^{26} \mathrm{En}$ esta misma nave había un retablo dedicado a san José, ${ }^{27}$ con Jesús de la mano, cuya imagen procedía de la iglesia de Santo Domingo, de Carmona, y seguramente llegó a este templo después del incendio de 1936. En la cabecera de la nave de la epístola, había un retablo del siglo XVIII con una «historia pictórica de la Coronación de Nuestra Señora, y la imagen yacente de la Virgen», fechable esta última en el siglo XVIII; actualmente, este retablo alberga una escultura moderna de la Asunción de la Virgen en vez de dicha historia pictórica. En esta nave había también un retablo moderno con una imagen de san Francisco de Paula, que podría datarse a finales del siglo XVIII «con aureola y atributos de plata, traje de terciopelo bordado y rosario de cristal de roca». ${ }^{28} \mathrm{~A}$ los pies de la nave central del templo, bajo el coro, se abría la capilla de Ntra. Sra. de Consolación, imagen de vestir del siglo XIX, en un retablo del último cuarto del siglo XVII. Repartidos por la nave, había varios cuadros con escenas de la vida de san Francisco de Paula, todos del siglo XVIII.

La torre está construida con ladrillo visto y azulejos y tiene tres cuerpos y chapitel; el último cuerpo tiene friso con la siguiente inscripción: «acabóse... F. Gerónimo Ortiz»; la veleta tiene la leyenda de Charitas, propia de la orden mínima y la campana tiene una imagen en relieve de la Virgen de la Victoria y la siguiente inscripción: «Se hizo siendo corr. de este convento del Sr. S. Sebastián, orden de mínimos, de la villa de Arahal, el M.R.P. Fr. Gabriel Sevillano, lector jubilado y examinador sinodal, año 1796. La fundió Joaquín de Herrera en su fábrica de Sevilla». La portada principal, a los pies de la nave tiene en su remate una hornacina con la escultura de san Francisco de Paula; la portada de acceso al claustro es de finales del siglo XVII. ${ }^{29}$

En el informe elaborado por la Junta de Cultura Histórica y Tesoro Artístico de Sevilla, se narra así el estado en que quedó el templo tras los sucesos de julio de 1936: ${ }^{30}$

\footnotetext{
${ }^{25}$ Este retablo fue costeado por doña Dolores Zayas, viuda de don José Zayas Caro. Cfr. Antonio Jiménez Pérez, Notas históricas..., 73.

${ }^{26}$ Cfr. VV. AA., Inventario artístico de Sevilla y su provincia, Madrid, 1985, t. II, 135.

${ }^{27}$ Hoy se encuentra sustituyendo a la imagen de la Virgen del Carmen, en el retablo neoclásico. Cfr. Idem.

${ }^{28}$ Ibídem, p. 137.

${ }^{29}$ Cfr. Ibídem, pp. 133-135.

${ }^{30} \mathrm{VV}$. AA., Edificios religiosos y objetos de culto saqueados y destruidos por los marxistas en los pueblos de la provincia de Sevilla, Sevilla, 1937, 45-46.
} 
Saqueado el 19 de julio de 1936 e incendiado en la calle el producto del saqueo. El edificio no ha sufrido deterioro de importancia. Se han perdido algunos retablos laterales, conservándose el mayor y algunos otros, todos del siglo XVIII, con mutilaciones fáciles de subsanar. El retablo de la capilla de Ntra. Sra. de Consolación, de fines del siglo XVII, sufre importantes destrozos en sus soportes y decoración. Las imágenes fueron destrozadas en su totalidad; respetando, en cambio, los lienzos de pintura repartidos en la iglesia y destrozando los que se hallaban en el claustro.

Es posible que entre los cuadros destrozados estuviera el resto de la serie pictórica sobre la vida del santo fundador, serie que tradicionalmente constaba de doce cuadros y que hallamos en otros conventos de la orden.

\section{DE LOS FRAILES QUE HABITARON ESTE CONVENTO}

En cuanto al número de efectivos que componían la comunidad de este convento, el dato más antiguo lo proporciona el P. Montoya (1619), quien decía que era convento «de casi cuarenta religiosos»; más de un siglo después, el Catastro de Ensenada (1751) hablaba de una comunidad de 18 miembros. En un informe de 1764 se dice que la comunidad estaba formada por quince sacerdotes, cinco coristas y dos legos, lo que hacía un total de 22 religiosos; once años después, el informe del P. Cabrera (1775) volvía a establecer en 18 el número de miembros de la comunidad. Hacia finales de este siglo, en 1783, la comunidad la formaban solamente 11 religiosos $^{31} \mathrm{y}$ en el siglo XIX el único dato que manejamos es que en vísperas del cierre temporal del convento en 1821, sus moradores eran 7 religiosos ordenados «in sacris».

Las antiguas crónicas de la orden mínima tan sólo recogen una breve reseña de un religioso, hijo de este convento, destacado en este caso por el martirio a que fue sometido antes de su muerte; se trata de fray Juan Bejel natural del Arahal y que había profesado en el convento de su villa natal. Estando residiendo en el convento de Granada, fue destinado al de Sevilla y por el camino fue asesinado por unos moriscos granadinos, como a cuatro leguas y media de la ciudad. Sucedió su martirio en octubre de 1568 , en pleno levantamiento de los moriscos del reino granadino. ${ }^{32}$

\footnotetext{
${ }^{31}$ Archivo Municipal de Sevilla (en adelante, AMS), sección XI, tomo 1 E, expediente $\mathrm{n}^{\circ} 31$. Plan que demuestra los conventos de Religiosos Mínimos de S. Francisco de Paula que hay en esta Provincia, con el número de los que en el día mantiene, las Rentas que tiene cada uno al año, los que pueden existir dando a cada individuo la cantidad de 2.200 reales al año para su subsistencia y el sobrante que queda a cada convento, por no llegar a esta cantidad, Sevilla, 13 de septiembre de 1783.

${ }^{32}$ Fr. Lucas de Montoya, Crónica General, libro IV, 284-285.
} 
De otros religiosos moradores de este convento durante el siglo XIX hemos tenido noticia a través de la documentación custodiada en el archivo del arzobispado hispalense: ${ }^{33}$

Fray Juan José Gallego: natural de Arahal y profeso del convento de su villa natal; en la orden alcanzó el grado de predicador jubilado, teniendo además otros títulos, como el de examinador sinodal del arzobispado hispalense y el de calificador del Santo Oficio; ejerció de corrector del colegio san Francisco de Paula de Sevilla y de otros conventos desde el año 1804 y también de definidor provincial. El 29 de marzo de 1810, en los inicios de la ocupación francesa de la villa, adonde estableció su residencia en virtud de la aplicación de las normas exclaustradoras dictadas por el gobierno napoleónico, dirigió una exposición al gobernador del arzobispado hispalense, don Manuel Cayetano Muñoz y Benavente, de quien precisamente había recibido el título de examinador sinodal, en la que solicitaba ser agregado a la parroquia de Santa María Magdalena y se le diesen licencias para poder ejercer como sacerdote. Las autoridades eclesiásticas recabaron un informe sobre la conducta de este religioso al vicario de Arahal, don Pedro de Ortiz, antes de proceder a otorgarle lo que solicitaban; el citado informe lleva fecha de 20 de abril de 1810 y en el mismo se dice lo siguiente:

El suplicante dice verdad en todo lo que expone en el memorial; es sacerdote de la mejor conducta y arreglo, como tengo informado a V.S., y cerciorado de los religiosos de su orden las disensiones que ha habido en la Religión, han sido acerca de la elección de provincial y empleos de la orden; y unos dicen que el P. Pretendiente, llevado de razón, ha sido de partido, y otros, que se ha manifestado indiferente; pero esto ha sido para este público de ningún momento con respecto a su conducta, y así, lo hallo acreedor y bastantemente útil a las almas que dirige, que son muchas, a que Su Ilma. le conceda las licencias que solicita. Esto es lo que en conciencia puedo informar.

Por lo que, a la vista del informe del vicario, accedieron a su solicitud.

Fray Alonso Ramos: el 9 de noviembre de 1810, el vicario de Arahal, don Pedro de Ortiz, solicitó por escrito al comisario regio de Sevilla, don Blas de Aranza, que se le reintegrasen a este ex regular sus licencias ministeriales debido a la «falta grande de ministros hábiles para predicar y confesar como se advierte continuamente los más de los días y principalmente en los de alguna concurrencia por ser escaso el número de confesores»; por esta exposición sabemos que fray Alonso, natural de Arahal, había sido lector de filosofía durante tres años en la cátedra pública existente en el convento de esta villa, que la orden tenía dotada «para beneficio de los jóvenes que querían dedicarse a las letras». Sobre

${ }^{33}$ Todos los datos en AGAS, Gobierno, Órdenes Religiosas Masculinas, legajo 14, expediente 1; legajo 15 , expediente 3 ; legajo 20 , expediente 3 ; legajo 25 , expedientes 1 y 2 . 
la conducta de este religioso, el vicario se expresa en los siguientes elogiosos términos:

Siendo hombre de una vida acreditada en el desempeño de sus obligaciones y de una capacidad aprobada, tanto por el cuerpo eclesiástico de esta villa y de cualesquiera otras donde ha morado, como por el civil, de quienes por su conducta y decencia tiene granjeadas sus voluntades en un todo.

El comisario regio respondió que por su parte no existía impedimento a la solicitud, por lo que se le despacharon las licencias de confesar y predicar el 21 de noviembre de aquel año.

Fray Antonio Caballero Guillena: natural de Arahal, nació el 14 de mayo de 1790, siendo bautizado ese mismo día en la parroquial de Santa María Magdalena de Arahal, imponiéndosele los nombres de Antonio Manuel Francisco de Paula Bonifacio, hijo de Andrés Caballero, natural de Osuna, y $\mathrm{M}^{\mathrm{a}}$ del Refugio Guillena, natural de Arahal; perteneció al convento de mínimos de aquella villa, siendo ordenado sacerdote el 18 de febrero de 1815 «en las témporas de Ceniza». Se secularizó el 4 de agosto de 1821, siendo su benévolo receptor don Pedro de Vera y Delgado, provisor y vicario capitular de Sevilla, entonces sede vacante, asignándosele una pensión de tres reales diarios. En 1850, con 60 años de edad, seguía cobrando la pensión del gobierno, cinco reales diarios, y no desempeñaba ningún cargo ni empleo, estando asignado a la parroquia de su villa natal. El 9 de septiembre de 1855, con 65 años de edad, dirigió desde Arahal una petición al gobernador eclesiástico del arzobispado hispalense para que lo relevase de sus tareas en la parroquia, dada su avanzada edad y sus achaques, que le imposibilitaban «para cumplir con su ministerio activo y sí sólo con el pasivo de celebrar y confesar, y esto en los días que el padecer se lo permite». Según el certificado médico que acompañaba a la solicitud, expedido por el profesor de medicina de Arahal don Juan Antonio Huertas, había padecido en el transcurso de seis años «de una artritis crónica» y además era miope. Falleció en Arahal el 9 de diciembre de 1859, a los 68 años de edad. ${ }^{34}$

Fray Francisco Jiménez Ocampo: nació en Arahal en 1778; profesó en la orden de los mínimos en el convento de su villa natal, ordenándose sacerdote en 21 de septiembre de 1805; ejerció el oficio de predicador, en el que llegó a alcanzar el grado de jubilado. Obtuvo su secularización perpetua el 27 de julio de 1821, residiendo en el convento arahalense y siendo su benévolo receptor don Pedro de Vera; desde entonces se le asignó la pensión de tres reales diarios que no dejó de cobrar y que para el año 1850 ascendía a seis reales diarios. En

${ }^{34}$ Boletín Oficial de Arzobispado de Sevilla (en adelante, BOAS), (1859) 287.

Hispania Sacra, LXVII

135, enero-junio 2015, 197-218, ISSN: 0018-215X, doi: 10.3989/hs.2015.005 
dicho año, cuando contaba con 72 años de edad, residía en Arahal y no tenía ningún cargo parroquial ni eclesiástico.

Fray José Rodríguez Jiménez: nació en Arahal el 5 de agosto de 1778, hijo legítimo de Manuel Rodríguez y María Jiménez, naturales y vecinos de dicha villa; ingreso en la orden de los mínimos, donde se ordenó sacerdote «en las témporas de san Mateo de 1802», llegando a alcanzar el empleo de predicador jubilado en el convento de su pueblo natal, donde se secularizó el 13 de septiembre de 1822, siendo su receptor don Pedro de Vera, asignándosele la pensión respectiva, que cobró hasta el 2 de septiembre de 1827 por haber sido nombrado teniente de cura propio en la parroquia de Arahal. Renunció a su cargo pastoral el 14 de septiembre de 1848 «por su edad y achaques», volviendo entonces a cobrar la pensión asignada como secularizado, ya de seis reales diarios y no desempeñando desde entonces ningún otro cargo. En 1855, con 77 años de edad, respondió a la orden del arzobispado para colocación de los exclaustrados que no podía «ejercer ningún ministerio activo, sólo celebrar y confesar los días que se lo permite su padecer»; según el certificado médico que acompañaba, firmado por don José Herrera, médico cirujano titular de Arahal, padecía «de asma húmeda, teniendo exceso agudos a menudo, en términos de llevarse dos terceras partes del año completamente impedido, y cuando mejor se halla apenas puede andar algo por la disnea considerable». Falleció en Arahal el 12 de junio de 1859, a los 80 años de edad. ${ }^{35}$

Fr. Francisco Gutiérrez Sánchez: religioso lego profeso, exclaustrado del convento de Arahal; según certificado médico de 2 de septiembre de 1836, en esa fecha contaba «más de setenta años» de edad, residía en Arahal y se encontraba «imposibilitado para caminar sin molestia, por haber padecido de perlesía que le ocupó su lado derecho, cuya pierna permanece adoleciendo de falta de movimiento, debido así por su mucha edad referida como por la prolongada duración de este mal».

En diciembre de 1835 había otorgado un poder, en unión de otros ex religiosos que componían la comunidad de Arahal, a favor de fray Manuel Mellado «religioso que fue del mismo orden, también exclaustrado de su convento de la ciudad de Sevilla y vecino de ella» para que en nombre de ellos pudiera «percibir y cobrar todas y cualesquiera cantidades de metálico que por razón de la asignación que les estaba hecha por el Gobierno les correspondiese, tanto de las devengadas como las que se fuesen venciendo».

Por una fe de vida firmada por el alcalde $1^{\circ}$ y el vicario de Arahal, fechada el 20 de marzo de 1837, sabemos que Fr. Francisco todavía seguía residiendo en dicha villa y que entonces no disfrutaba de «ningún sueldo ni pensión de

\footnotetext{
${ }^{35}$ BOAS (1859) 27.
} 
ninguna clase, más que la asignación que como tal exclaustrado le está hecha por el Gobierno».

Fray José Ma Marchante Benítez: natural de Medina Sidonia (1808); fue ordenado presbítero el 18 de diciembre de 1833 «en las témporas de Adviento» y en el claustro ejerció de predicador; era conventual de Arahal al tiempo de la exclaustración. En 1846 fue nombrado cura ecónomo de la parroquial de Almadén de la Plata, y en este cargo permaneció al menos hasta 1850.

Fray Andrés Tamariz Vega: nació en Arahal el 7 de enero del año 1782; fue ordenado sacerdote en las «témporas de Ceniza» del año 1806 y ejerció en la orden como predicador, llegando a ser jubilado; fue exclaustrado del convento de su villa natal el 23 de septiembre de 1835, del cual había sido corrector el año 1821. Tras la exclaustración, fijó su residencia en esta villa, no desempeñando ningún cargo ni beneficio eclesiástico, por lo que cobraba la pensión de seis reales diarios. En 1855, a la edad de 73 años, todavía seguía residiendo en Arahal, asignado a la parroquia, pero se encontraba imposibilitado para desempeñar ningún cargo pastoral, como lo acreditaba el certificado médico de don José $\mathrm{M}^{\mathrm{a}}$ de Reina, profesor de medicina, pues sufría «un catarro crónico pulmonar, el cual por cierto tiempo se agudiza y le impide absolutamente el poder salir ni andar ni menos poder celebrar el santo sacrificio de la misa»; un informe del arcipreste de Arahal, fechado 15 de octubre del mismo año, venía a corroborar lo certificado por el médico: «digo que D. Andrés Tamariz (...) está muy corto de vista, razón por la cual y sus padecimientos, hace ya cerca de dos años no celebra en santo sacrificio de la misa». Falleció en Arahal el 7 de abril de 1859, a los 77 años de edad. ${ }^{36}$

\section{CONCLUSIONES}

A lo largo de las páginas anteriores hemos podido constatar cómo el convento de Nuestra Señora de la Victoria de Arahal fue un convento plenamente integrado en la población a la que servía. El auxilio espiritual de los fieles fue su actividad principal, a la que acompañaba la meritoria labor de sostenimiento de una cátedra de filosofía durante prácticamente toda su existencia, de la que también se beneficiaron los hijos del pueblo.

Económicamente hablando, el convento de Arahal era el más rico en propiedades de entre todos los que la orden tenía en esta parte de Andalucía, siendo bastante extensas las propiedades rústicas que poseía, no sólo en el término arahalense.

${ }^{36}$ BOAS, (1859) 378. 
En el terreno artístico, el patrimonio que ha llegado hasta nosotros, después de alguna que otra devastación, nos habla de una más que notable riqueza artística, en consonancia con la riqueza patrimonial de la comunidad mínima del Arahal, hallándose todavía huellas del pasado mínimo en el templo, tales como las diferentes representaciones del santo fundador que se encuentran en el mismo, tanto en escultura como en pintura.

\section{FUENTES}

AGAS, Gobierno, Órdenes Religiosas Masculinas, legajo 4, expediente 20, legajo 8, expediente 3, legajo 14, expedientes 7-A y 7-B, legajo 15, expediente 3 .

AMO, bolsa n ${ }^{\circ}$, de Morón, Cote y El Arahal, legajo nº 3, nº 2.

AMS, sección XI, tomo 1 E, expediente $n^{\circ} 31$.

\section{BIBLIOGRAFÍA}

Acta capitulorum generalium ordinis minimorum, Roma, 1916, vol. I.

Bago y Quintanilla, M. de, Aportaciones documentales (segunda serie), en Documentos para la Historia del Arte en Andalucía, Sevilla, 1929, vol. II.

Jiménez Pérez, A., Notas históricas de Arahal, s/1, 1972. 1929.

López Martínez, C., Desde Jerónimo Hernández hasta Martínez Montañés, Sevilla,

Martinez Carretero, I., o carm., El Carmen del Buen Suceso de Sevilla, Sevilla, 2005.

Montoya, Fr. L. de, om, Crónica General de la Orden de los Mínimos de S. Francisco de Paula, Madrid, 1619.

Morales, Fr. J. de, Epítome de la fundación de la provincia de Andalucía de la orden de los Mínimos del glorioso patriarca San Francisco de Paula, Málaga, 1619.

Nieto Jiménez, P.A., Don Juan Leonardo Malo Manrique y el barroco colonial en Arahal, en VV. AA., Actas de las IV Jornadas de historia sobre la provincia de Sevilla, Sevilla, 2007.

Ramos Suárez, M.A., El patrimonio cultural de Marchena y la ocupación napoleónica, Marchena, 1999.

VV. AA., Edificios religiosos y objetos de culto saqueados y destruidos por los marxistas en los pueblos de la provincia de Sevilla, Sevilla, 1937. tomo I.

VV.AA., Catálogo arqueológico y artístico de la provincia de Sevilla, Sevilla, 1939, 
VV. AA., Guía artística de Sevilla y su provincia, Sevilla², 2004, tomo II.

VV. AA., Inventario artístico de Sevilla y su provincia, Madrid, 1985, tomo II. 